\title{
Effects of the Oral Administration of a Probiotic Combination on the Expression of Cytokine and the Histopathology of the Large Intestine in an Animal Model of Enteritis
}

\author{
Jae-Gu Seo, Myung-Jun Chung, and Hyun-Gi Lee* \\ R\&D Center, Cellbiotech Co., Ltd., Gimpo 415-871, Korea
}

\begin{abstract}
It is known that lactic-acid bacteria (LAB) helps keeping the intestine healthy and to enhance its immunologic competence. In addition, it is known to control the composition of the enterobacteria and the intestinal inflammatory reaction by inducing immunological enhancement. This study was performed, in a mouse model, to test the treatment and preventive effects of LAB of inflammatory bowel disease (IBD), which was induced by a blend of LAB-administering trinitrobenzene sulfonic acid (TNBS). To obtain the animal model of IBD, 2\% TNBS was rectally administered once to a five-week-old male Balbc/J mouse. A probiotic combination was administered to the prevention group five times a week for eight weeks before the inducement of enteritis, and the mixture was administered to the treatment group five times a week, after the administration of TNBS. The changes in the levels of the cytokines of the lymph nodes and the tissue of the large intestine were observed, both with the naked eye and with a microscope. The observation showed that the levels of inflammatory cells, infiltration, and necrosis were much lower in the LAB-administered groups than in that of the control group. In addition, the inflammatory cytokines (e.g., TNF- $\alpha$, IL-17A) decreased in the lymph nodes and the tissues of the large intestine. The results indicated that the administration of the combination to the animal model suppressed the inflammatory cytokines in the large intestine and in the lymph nodes, which in turn suppressed the progression of colitis.
\end{abstract}

Key words: Lactic-acid bacteria, inflammatory bowel disease, trinitrobenzene sulfonic acid, inflammatory cytokine

\section{Introduction}

There is no established treatment for inflammatory colitis, and its cause and pathophysiology are unclear. Although many studies have tried to identify the cause and pathophysiology of inflammatory coliti, the rarity of animal models with pathological conditions similar to those of inflammatory colitis limited such studies. It was reported that acetic acid or trinitrobenzene sulfonic acid (TNBS) induced colitis in rats. Particularly, the finding that TNBS induced a lesion similar to human inflammatory colitis in experimental animals accelerated studies on the pathophysiology and treatment of inflammatory colitis (Kim et al., 1996; Morris et al., 1989; Yamada et al., 1992).

Cytokine is secreted by various types of cells in the body and is involved in the proliferation, differentiation, and activation of cells. If it is in the form of polypeptides

*Corresponding author: Hyun-Gi Lee, Cellbiotech, Gimpo 415872, Korea. Tel: 82-31-987-6205; Fax: 82-31-987-8102, E-mail: hglee@cellbiotech.com or glycoprotein, it plays a critical role in immune response and inflammatory reaction. One thing common too many etiologies of various immune disorders is the production of cytokine, which controls the immune response or damage or recovery of tissues, although the types of clinical manifestations of such immune disorders are diverse (Andreakos et al., 2002).

In patients with inflammatory intestinal disease (IBD), the levels of pro-inflammatory cytokines such as IL-1 $\beta$ and TNF- $\alpha$ are high. These cytokines are reported to play a key role in continuing and amplifying the inflammatory response of the mucous membrane. The study of the factors involved in the production and activation of such cytokines is important in the pathophysiology and treatment of IBD (Sartor, 1997). Besides, both IL-8 and macrophage colony-stimulating factor (GM-CSF) are the cytokines that can promote the release of leukocytes from the bone marrow, produce an acute phase reactant in the liver, and stimulate the vascular endothelium (Bussolino et al., 1991; Gabay and Kushner, 1999; Platzer, 1989). In particular, it is known that Th17 cells secrete IL-17A and 
IL-17F both in humans and mice, and are involved in the activation of neutrophils and in the creation of inflammatory cytokine and chemokine (Weaver et al., 2007).

It was reported that the inflammation in IBD could be triggered by the abnormal fermentation of pathogenic bacteria in the intestine, and by an imbalance between the resident bacteria. It is known that the concentration of beneficial bacteria such as lactic-acid bacteria (LAB) and bifidobacteria is low in patients with active ulcerative colitis or Crohn's disease when examined based on the histology of the colon or feces (Fabia et al., 1993; Favier et al., 1997). This suggests that maintenance of the intestinal bacterial flora or rectification of abnormal fermentation can prevent or treat IBD. Thus, this study was conducted to investigate the effects of a probiotic combination on IBD in a mouse model that was induced by TNBS, by observing the change in the expression of the inflammatory cytokine and the lesion of the colon, and by studying the possibility of the prevention and treatment of the inflammation.

\section{Materials and Methods}

\section{Bacterial strains}

The bacterial strains were Lactobacillus casei (KTCT 11863BP), Lactobacillus acidophilus (KTCT 11906BP), Streptococcus thermophilus (KTCT 11870BP), and Bifidobacterium lactis (KTCT 11903BP), and they were isolated from human feces, except for $L$. casei, which was isolated form a dairy product. The strains were mixed to generate a combination in the same ratio. The combination was orally administered to mice at the dose of $1 \times 10^{6}$ and $1 \times 10^{8}$ colony-forming units $(\mathrm{CFU}) / \mathrm{d}$.

\section{Induction of colitis in the animal subjects}

Five-week-old Balbc/J male mice were purchased from Central Lab. Animal Inc. Korea and were acquainted with the environment for one week. During the experiment, the temperature and humidity were kept at $23 \pm 1^{\circ} \mathrm{C}$ and $55 \pm 10 \%$, respectively, with a $12 \mathrm{~h}$ light/dark cycle. The diet and water were provided ad libitum. This study was approved by the Animal Experiment Ethics Committee (CBTA-004) and complied with the Regulations on Animal Management. All the experiment protocols in this study were reviewed and approved by the Animal Care and Use Committee of Cellbiotech Co., Ltd. of Korea.

For the induction of colitis, a TNBS solution ( $2 \%$ in $50 \%$ ethanol) was introduced to the colon through the anus at the dose of $500 \mu \mathrm{L}$ per $\mathrm{kg}$ of body weight, using a 5-cm long polyethylene cannula (Becton Dickinson, USA) attached to an $1 \mathrm{~mL}$ syringe that contained the solution. After the infusion, the mouse was positioned head-to-ground for $1 \mathrm{~min}$. Ten mice were randomly assigned to four groups: the normal, control, treated, and prevented groups. The normal group was treated with $50 \%$ ethanol. The mixture was administered to the mice for eight weeks (five times a week) before the TNBS treatment (prevented group), or to the mice treated with TNBS (treated group) for one week (five times a week) after the induction of colitis by TNBS.

\section{Collection of colon tissue samples}

The mice were etherized after $12 \mathrm{~h}$ fasting, and then the colons were extracted. The colon was cut into three pieces, and the piece farthest from the cesium was sliced to observe the colon tissues, which were then washed three or four times with PBS at $0^{\circ} \mathrm{C}$ and then stored at $-70^{\circ} \mathrm{C}$ until use. The tissue samples were fixed in a $10 \%$ formalin solution and were stored at $4^{\circ} \mathrm{C}$ for hematoxylin-eosin (H\&E) staining.

\section{Measurement of the cytokine mRNA levels via RT- PCR}

The cytokine mRNA levels in the extracted tissues were measured via RT-PCR. The tissues were homogenized, and the RNA was separated with a TRI reagent (Sigma, USA). cDNA was synthesized with Superscript II Firststrand Synthesis Kit (Invitrogen, USA), and $2 \mathrm{ml}$ of the cDNA was used to determine the levels of TNF- $\alpha$ and IL-17A using cytokine-specific primers (Table 1).

Table 1. List of mouse gene-specific primers in RT-PCR

\begin{tabular}{|c|c|c|c|c|}
\hline \multicolumn{2}{|c|}{ Genes } & Sequence $\left(5^{\prime}-3^{\prime}\right)$ & Accession Number & PCR product \\
\hline TNF- $\alpha$ & $\begin{array}{l}\text { Forward } \\
\text { Reverse }\end{array}$ & $\begin{array}{l}\text { CAT CTT CTC AAA ATT CGA GTG ACA A } \\
\text { TGG GAG TAG ACA AGG TAC AAC CC }\end{array}$ & AB185894 & $195 \mathrm{bp}$ \\
\hline IL-17A & $\begin{array}{l}\text { Forward } \\
\text { Reverse }\end{array}$ & $\begin{array}{l}\text { GCT CCA GAA GGC CCT CAG A } \\
\text { CCT TCC CTC CGC ATT GAC A }\end{array}$ & NM_010552 & $110 \mathrm{bp}$ \\
\hline GAPDH & $\begin{array}{l}\text { Forward } \\
\text { Reverse }\end{array}$ & $\begin{array}{l}\text { GGA GAT TGT TGC CAT CAA CG } \\
\text { ATG ATG ACC CTT TTG GCT CC }\end{array}$ & NM_008084 & $279 \mathrm{bp}$ \\
\hline
\end{tabular}


Quantitative real-time PCR was performed using LightCycler DNA Master SYBR Green I via the LightCycler 480 system (Roche Diagnostic, Germany). The reaction mixture contained $1 \mu \mathrm{L}$ cDNA as a template, $4 \mathrm{mM}$ $\mathrm{MgCl}_{2}$, and $0.5 \mu \mathrm{M}$ primer. The relative expression was quantified from the change in the cycle threshold method $(\Delta \Delta \mathrm{Ct})$, and is presented in this paper as the fold induction, with the control samples set at the expression index of 1 .

\section{Microscopic observation of the colon tissue}

The colon tissues described above were also used to examine the thickness and eruptions in the mucosa and ulcer. For the pathological observation, the tissues were fixed in a $10 \%$ formalin solution for 12-24 h, washed with water, dehydrated in alcohol (for $1 \mathrm{~h}$ each in 70, 80, 90 , and $100 \%$ concentrations) and xylene (three steps, $1 \mathrm{~h}$ for each step), and embedded in paraffin. The paraffin block was sliced $5 \mu \mathrm{m}$ thick, stained with H\&E, and observed under a microscope.

\section{Statistics}

The data were processed with Graphpad Prism ${ }^{\mathrm{TM}} 5.0$ (GraphPad Software, USA). The mean value and standard deviation were calculated in a group, and the significance was compared between the groups through the student t-test, where $p<0.05$ was considered significant.

\section{Results}

\section{Suppressive effect of LAB on inflammatory cytok- ine}

To identify the anti-inflammatory effect of lactobacillus, the mRNA expressions of IL-17A related to IBD were compared. The amount of mRNA expression of IL$17 \mathrm{~A}$ in the prevented group receiving $\left(1 \times 10^{8} \mathrm{CFU} /\right.$ mouse) was about eight times lower than in the control group, and it was significantly lower (by about 16 times) in the treated group $\left(1 \times 10^{8} \mathrm{CFU} /\right.$ mouse $)$. In contrast, the treated group $\left(1 \times 10^{6} \mathrm{CFU} /\right.$ mouse $)$ and the prevented group $\left(1 \times 10^{6} \mathrm{CFU} / \mathrm{mouse}\right)$ showed a tendency to have a decreasing level of IL-17A mRNA expression, although insignificant. The insignificant difference between the groups may have resulted from the decrease in sample size due to the death of the experimental animals during the experiment. The mRNA expressions of TNF- $\alpha$, an inflammatory cytokine, were also compared, and it was found that the amount of mRNA expression in the prevented group $\left(1 \times 10^{8} \mathrm{CFU} /\right.$ mouse $)$ was about 31 times lower than in the control group $(p<0.05)$ while the levels were about four and 16 times lower in the treated groups receiving $1 \times 10^{6}$ and $1 \times 10^{8} \mathrm{CFU}$, respectively, than in the control group ( $p$ value) (Fig. 1$)$.

\section{Gross examination and microscopic findings}

The gross examination of the mouse in which colitis was induced by TNBS showed no adhesion between the tissue of the large intestine and the lesion in all the groups with colitis. In the positive control (PC) group, however, the large intestine thickened due to the thickening of the mucous membrane, and hemorrhage due to ulcer was observed (Fig. 2).

It was found that the colitis lesions in the treated and prevented groups were improved much more than in the PC group (Fig. 2). The crypt cells in the tissue of the normal intestine were found to have disappeared more notably in the TNBS-treated control group than in the negative control (NC) group, and infiltration of inflammatory cells such as neutrophils and monocytes into the tissue was observed after the H\&E staining. Besides, much eosinophilic necrosis was observed, which indicates the pro-
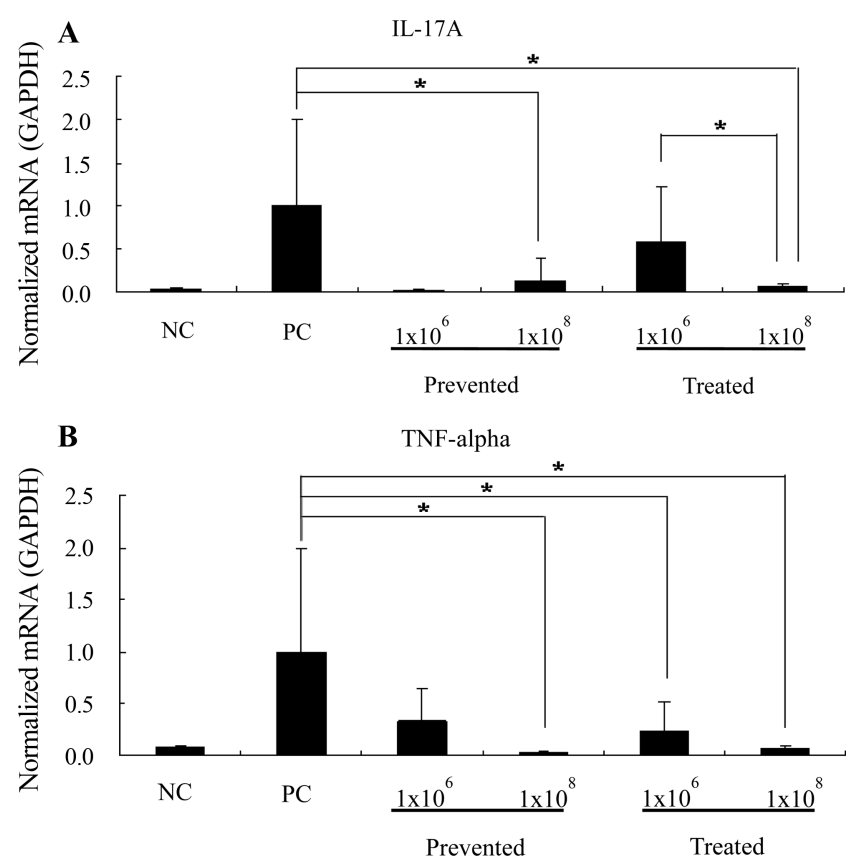

Fig. 1. Quantification of cytokine mRNA expressions in the colon tissues from each group. The error bars indicate the standard deviation. The relative expression was quantified from the change in the cycle threshold method $(\Delta \Delta \mathrm{Ct})$ and is presented in this paper as the fold induction, with the control samples set at the expression index of $1 .^{*} p<0.05$ as compared with the control group. The combination was orally administered to the experimental mice at the doses of $1 \times 10^{6}$ and $1 \times 10^{8} \mathrm{CFU} / \mathrm{d}$. A, IL-17A; $B, T N F-\alpha$. 

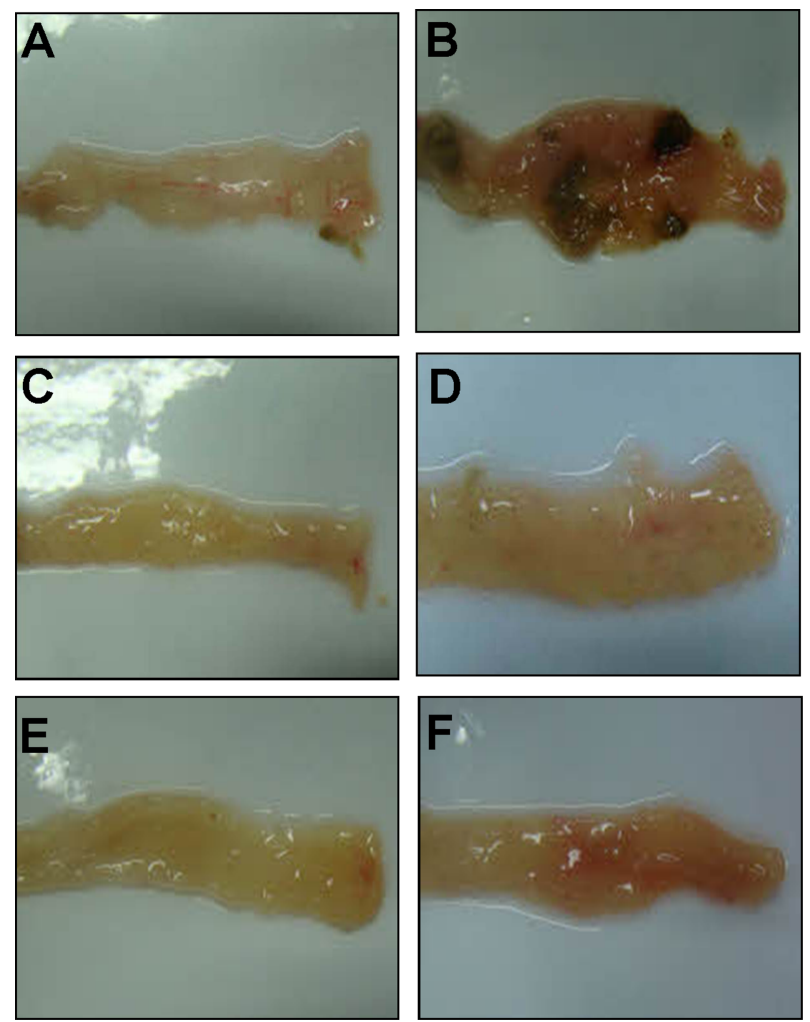

Fig. 2. Gross examination of the mice colitis induced by intracolonic PBS or TNBS administration. Hyperemia with thickening and ulceration are noticed, with grossly visible enlargement. The combination was orally administered to the experimental mice at the doses of $1 \times 10^{6}$ and $1 \times 10^{8} \mathrm{CFU} / \mathrm{d}$. A, normal; B, control; C, prevented $\left(1 \times 10^{6}\right)$; $\mathrm{D}$, prevented $\left(1 \times 10^{8}\right)$; E, treated $\left(1 \times 10^{8}\right) ; \mathrm{F}$, treated $\left(1 \times 10^{8}\right)$.

gression of serious colitis. In contrast, a larger number of normal crypt cells were observed in the combinationadministered groups than in the control group, and inflammatory reaction and necrosis were found to be low in the combination-administered groups, which indicate considerably mitigated enteritis. These results depended on the amount of the combination administered, and no difference was observed between the treated group and the prevented group (Fig. 3).

\section{Discussion}

Although the etiology and treatment method for IBD are unclear, the changes in the intestinal microflora are considered among the possible etiologies. Swidsinski et al. (2002) reported that the level of bacteria in the mucous membrane in an animal model with IBD was considerably higher than in the control group, and Ott et al. (2004) reported that the decrease in the number of normal anaerobic bacteria was related with inflammation of
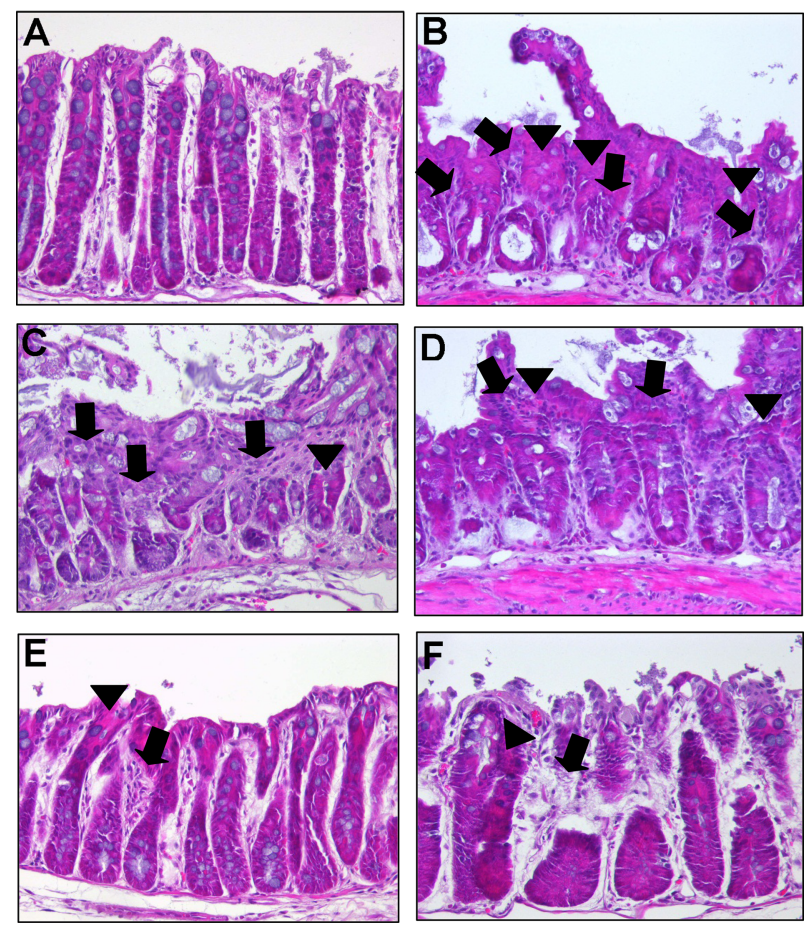

Fig. 3. Probiotics ameliorate the TNBS-induced colitis in the mouse colons. The arrowhead indicates the infiltration of inflammatory cells in the mucosa, and the arrow designates the mucosal destruction and severe infiltration of the inflammatory cells of the TNBS-induced colitis (H\&E; original magnification: 200X). The combination was orally administered to the experimental mice at the doses of $1 \times 10^{6}$ and $1 \times 10^{8} \mathrm{CFU} / \mathrm{d}$. A, normal; B, control; $\mathrm{C}$, prevented $\left(1 \times 10^{6}\right)$; D, prevented $\left(1 \times 10^{8}\right)$; E, treated $\left(1 \times 10^{8}\right) ; \mathrm{F}$, treated $\left(1 \times 10^{8}\right)$.

the mucous membrane in patients with IBD. Besides, Seksik et al. (2003) reported that the intestinal bacteria in patients with Crohn's disease were found to show more enterobacteria biodiversity than in healthy people, and that more than $30 \%$ of them were bacterial species that had not been identified phylogenically.

Administration of TNBS to experimental animals is known to form a covalent bond with the $\varepsilon$-amino group of lysine, a constituent of the mucous membrane, to produce modified cells. Macrophages recognize these modified cells and destroy them, which causes delayed hypersensitivity reaction. Th1 immune response modulated by the response of Th2 had been reported immunologically (Hoffmann et al., 2001; Neurath et al., 2000).

For the etiology of IBD, the immunological factors include inherent immunity, production of cytokines, and activation of $\mathrm{CD}^{+} \mathrm{T}$ cells. Studies on cytokine's functions in modulating inflammation and immune response are actively being conducted (Yeom et al., 2004). The levels of pro-inflammatory cytokines such as IL-1 $\beta$, IL-6, and 
TNF- $\alpha$ are high in the intestinal tissues of patients with IBD, and they play an important role in the pathology of the inflammation of the mucous membrane (Rogler and Andus, 1998).

From the histopathological aspect, the administration of TNBS with ethanol, a contact-sensitizing allergen, via the anus, may cause colitis. When TNBS comes in contact with the intestine, acute transmural necrosis due to oxidative damage may occur. Within several days of an enemy, acute necrosis and inflammation may occur, after which infiltration of neutrophils and monocytes, and chronic inflammation, may develop. The TNBS-induced colitis model includes anterior-wall ulcer. This TNBS-induced colitis model is advantageous in that it can induce chronic inflammation via the immunomechanism, which is similar to human inflammatory colitis.

In this study, the prevention and treatment effects of a probiotic combination were compared and analyzed, and no significant difference was observed at the mRNA level. The difference in terms of the mRNA expression of cytokine depending on the concentration of LAB that had been administered was significant only in the treated groups of IL-17A and had a tendency to decrease in the other groups, although insignificantly. To investigate the prevention and treatment effect of mixed $\mathrm{LAB}$, primers for cytokine (IL-1 beta and IL-6), in addition to IL 17A and TNF- $\alpha$, were prepared, and PCR was performed, but no specific band was observed.

It is expected that to overcome the error rate, studies should be accompanied by cell sorting so that the change in the level of the cytokine could be more precisely identified. Quantitative identification of the level of cytokine in terms of protein, by comparing the mRNA expressions and performing ELISA and Western blotting, is required to more precisely test the effect of mixed LAB.

In this study, crypt cells of normal intestinal tissue more significantly disappeared in the TNBS-administered PC group than in the normal group, and infiltration of inflammatory cells such as neutrophils and monocytes was observed. Also, after the tissue staining, much eosinophilic necrosis was observed, which indicated the progression of severe enteritis.

For IBD, the LAB-administered group exhibited a much lower level of infiltration of inflammatory cells and necrosis than the control group. Both the $1 \times 10^{8}$-CFU-administered prevention and treatment groups showed significantly greater improvement than the $1 \times 10^{6}$-CFU-administered groups in terms of histopathology, as in the case of the cytokine mRNA level in the large-intestine tissue.
Taken together, the administration of the mixed LAB to the experimental models in which colitis was induced by the administration of TNBS decreased the level of mRNA expression of cytokine in the $1 \times 10^{8} \mathrm{CFU}$ groups, which improved their colitis. It has been suggested that the probiotic LAB play a role in the suppression of the progression of colitis by inhibiting the expression of inflammatory cytokines in the large intestine, and improve lesions such as the thickened mucous membrane and infiltration of inflammatory cells. Thus, the administration of mixed LAB $\left(1 \times 10^{8} \mathrm{CFU}\right)$ is considered to have an anti-inflammatory effect on colitis. The existing literatures expound on the beneficial effects of LAB. More recently, the role of LAB in the immune system was reported. In this study, intestinal inflammation caused by LAB has been shown to improve the effectiveness of four types of LAB. The combination utilized in the daily product offers an advantage, manifesting improvement in the symptoms of IBD patients.

\section{Acknowledgement}

This study was partly supported by a grant (No. 10026108) from the Ministry of Knowledge Economy of the Republic of Korea.

\section{References}

1. Andreakos, E. T., Foxwell, B. M., Brennan, F. M., Maini, R. N., and Feldmann M. (2002) Cytokines and anti-cytokine biologicals in autoimmunity: present and future. Cytokine Growth Factor Rev. 13, 299-313.

2. Bussolino, F., Ziche, M., Wang, J. M., Alessi, D., Morbidelli, L., Cremona, O., Bosia, A., Marchisio, P. C., and Mantovani, A. (1991) In vitro and in vivo activation of endothelial cells by colony-stimulating factors. J. Clin. Invest. 87, 986-995.

3. Fabia, R., Ar'Rajab, A., Johansson, M. L., Andersson, R., Willen, R., Jeppsson, B., Molin, G., and Bengmark, S. (1993) Impairment of bacterial flora in human ulcerative colitis and experimental colitis in the rat. Digestion 54, 248-255.

4. Favier, C., Neut, C., Mizon, C., Cortot, A., Colombel, J. F., and Mizon, J. (1997) Fecal beta-D-galactosidase production and Bifidobacteria are decreased in Crohn's disease. Dig. Dis. Sci. 42, 817-822.

5. Gabay, C. and Kushner, I. (1999) Acute-phase proteins and other systemic responses to inflammation. N. Engl. J. Med. 340, 448-454.

6. Hoffmann, J. C., Peters, K., Henschke, S., Herrmann B., Pfister, K., Westermann, J., and Zeitz, M. (2001) Role of T lymphocytes in rat 2,4,6-trinitrobenzene sulphonic acid (TNBS) induced colitis: increased mortality after gammadelta $\mathrm{T}$ cell depletion and no effect of alphabeta $\mathrm{T}$ cell deple- 
tion. Gut 48, 489-495.

7. Kim, J. J., Ryu, J. K., Lee, D. H., Song, S. I., Kim, C. Y., and Kim, Y. I. (1996) The effect of anti-inflammatory drugs on colitis induced by trinitrobenzene sulfonic acid in rats. Korean J. Gastroenterol. 28, 224-231.

8. Morris, G. P., Beck, P. L., Herridge, M. S., Depew, W. T., Szewczuk, M. R., and Wallace, J. L. (1989) Hapten-induced model of chronic inflammation and ulceration in the rat colon. Gastroenterology 96, 795-803.

9. Neurath, M., Fuss, I., and Strober, W. (2000) TNBS-colitis. Int. Rev. Immunol. 19, 51-62.

10. Ott, S. J., Musfeldt, M., Wenderoth, D. F., Hampe, J., Brant, O., Folsch, U. R., Timmis, K. N., and Schreiber, S. (2004) Reduction in diversity of the colonic mucosa associated bacterial microflora in patients with active inflammatory bowel disease. Gut 53, 685-693.

11. Platzer, E. (1989) Human hemopoietic growth factors. Eur. J. Haematol. 42, 1-15.

12. Rogler, G. and Andus, T. (1998) Cytokines in inflammatory bowel disease. World J. Surg. 22, 382-389.

13. Sartor, R. B. (1997) Pathogenesis and immune mechanisms of chronic inflammatory bowel diseases. Am. J. Gastroenterol. 92, 5S-11S.
14. Seksik, P., Rigottier-Gois, L., Gramet, G., Sutren, M., Pochart, P., Marteau, P., Jian, R., and Dore, J. (2003) Alterations of the dominant faecal bacterial groups in patients with Crohn's disease of the colon. Gut 52, 237-242.

15. Swidsinski, A., Ladhoff, A., Pernthaler, A., Swidsinski, S., Loening-Baucke, V., Ortner, M., Weber, J., Hoffmann, U., Schreiber, S., Dietel, M., and Lochs, H. (2002) Mucosal flora in inflammatory bowel disease. Gastroenterology 122, 4454.

16. Weaver, C. T., Hatton, R. D., Mangan, P. R., and Harrington, L. E. (2007) IL-17 family cytokines and the expanding diversity of effector T cell lineages. Annu. Rev. Immunol. 25, 821852.

17. Yamada, Y., Marshall, S., Specian, R. D., and Grisham, M. B. (1992) A comparative analysis of two models of colitis in rats. Gastroenterology 102, 1524-1534.

18. Yeom, M.-J., Choi, B.-H., Han, D.-O., Lee, H.-J., Shim, I., Kim, S.-H., and Hahm, D.-H. (2004) In vitro inhibition of pro-inflammatory mediator mRNA expression by nephrite in lipopolysaccharide-induced mouse macrophage cells. Korean J. Oriental Physiol. Pathol. 18, 1622-1627.

(Received 2011.3.10/Revised 1st 2011.10.13, 2nd 2012.2.15, 3rd 2012.3.7/Accepted 2012.3.19) 